\title{
Penerapan Kalman Filter dalam Memperbaiki Error Object Tracking pada Brosur Berbasis Augmented Reality
}

\author{
Nurjayadi $^{1^{*}}$, Herwin ${ }^{2}$, Helda Yenni ${ }^{2}$ \\ ${ }^{1.2 .3}$ STMIK Amik Riau \\ Email : nurjayadi@stmik-amik-riau.ac.id
}

\begin{abstract}
Object Tracking is the process of following the position of the object. Noise needs to be reduced and even eliminated because the noise always appears in the process of sending information to each communication system. This results in the received information are often disturbed so that the results are not as expected. To overcome the noise in a digital image should be done the effort to improve the image quality. One method that can be used to reduce noise is Kalman Filter. This method has been proven by the previous reviewer to estimate a process through feedback control mechanism in the case of hand (motion) tracking, but the performance in terms of accuracy and response time on the system is still not good. In general, has been obtained an application in detecting an object image (brochure) in obtaining the measurement data. The data is obtained from the tracking camera to get the data tracking. In addition, the noise improvements are made using the Kalman Filter method to obtain stability information in the tracking process.
\end{abstract}

Keywords: Kalman Filter, Noise, Object Tracking, Image Tracking

\begin{abstract}
Abstrak
Object Tracking adalah proses mengikuti posisi dari suatu objek yang diinginkan. Noise perlu dikurangi bahkan dihilangkan karena noise selalu muncul dalam proses pengiriman informasi pada setiap sistem komunikasi. $\mathrm{Hal}$ ini mengakibatkan informasi yang diterima sering mengalami gangguan sehingga hasilnya tidak sesuai dengan yang diharapkan. Untuk mengatasi noise pada sebuah citra digital perlu dilakukan usaha untuk memperbaiki kualitas citra. Salah satu metode yang dapat digunaan untuk mengurangi noise adalah Kalman Filter. Metode ini telah dibuktikan oleh peneliti sebelumnya dalam mengestimasi sebuah proses melalui mekanisme control umpan balik dalam penerapan kasus hand (motion) tracking, tetapi performansi dari segi keakuratan dan waktu respon pada sistem masih kurang baik. Secara umum telah diperoleh sebuah aplikasi dalam mendeteksi sebuah objek image (brosur) dalam memperoleh data pengukuran. Data diperoleh dari hasil tracking camera sehingga diperoleh data tracking. Selain itu diperoleh perbaikan noise dengan menggunakan metode kalman filter sehingga diperoleh informasi kestabilan dalam proses tracking.
\end{abstract}

Kata kunci : Kalman Filter, Noise, Object Tracking, Image Tracking

\section{Pendahuluan}

Object Tracking adalah proses mengikuti posisi dari suatu objek yang diinginkan [1]. Noise perlu dikurangi bahkan dihilangkan karena Noise selalu muncul dalam proses pengiriman informasi pada setiap sistem komunikasi. Hal ini mengakibatkan informasi yang diterima sering mengalami gangguan sehingga hasilnya tidak sesuai dengan yang diharapkan. Untuk mengatasi noise pada sebuah citra digital perlu dilakukan usaha untuk memperbaiki kualitas citra [2].
Metode Median Filter [3], Watershed [4], Kalman Filter [5], diusulkan oleh banyak peneliti dalam mengurangi noise.

Median Filter terbukti dalam mengeliminasi noise, tetapi penggunaan median filter itu sendiri juga mempunyai suatu kelemahan yaitu gambar yang sudah diproses akan tampak sedikit blur atau kabur [3],Watershed merupakan metode segmentasi yang cukup akurat untuk mendapatkan daerah yang merupakan objek yang di segmentasi. Tetapi terdapat kelemahan dari transformasi watershed yaitu adanya segmentasi yang 
berlebihan (over segmentation) sehingga objek yang didapat lebih banyak dari objek yang diharapkan [4].

Pada Gambar 1, Kalman Filter dapat memecahkan masalah Median Filter dan Watershed, yaitu mengestimasi sebuah proses melalui mekanisme control umpan balik. tetapi penggunaan kalman filter dalam penerapan kasus hand (motion) tracking menghasilkan performansi dari segi keakuratan dan waktu respon pada sistem masih kurang baik [5].

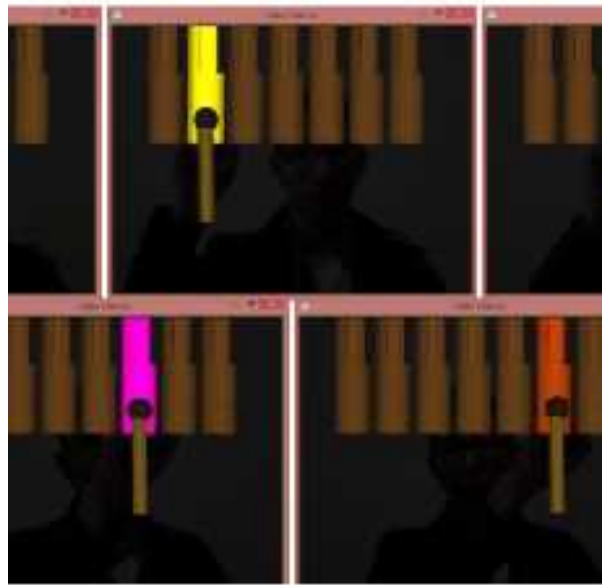

Gambar 1. Penelitian Analisis dan Implementasi Hand Tracking Menggunakan Kalman Filter pada Augmented Reality

Sementara pada penelitian yang lain, seperti yang terlihat pada gambar 2 dan gambar 3, penerapan teknologi brosur berbasis augmented reality diperlukan jarak dan sudut yang ideal dalam proses pelacakan markerless untuk memperoleh tampilan yang baik [6]. Penerapan kalman filter digunakan untuk memecahkan permasalahan pada penelitian tersebut dalam menghilangkan nilai error sebuah object tracking.

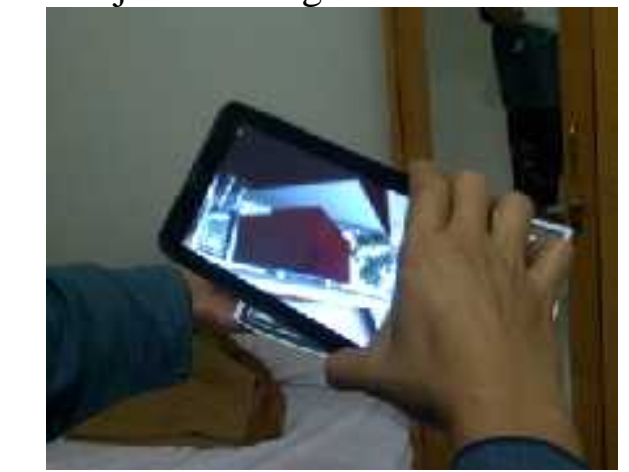

Gambar 2. Proses object tracking brosur berbasis augmented reality

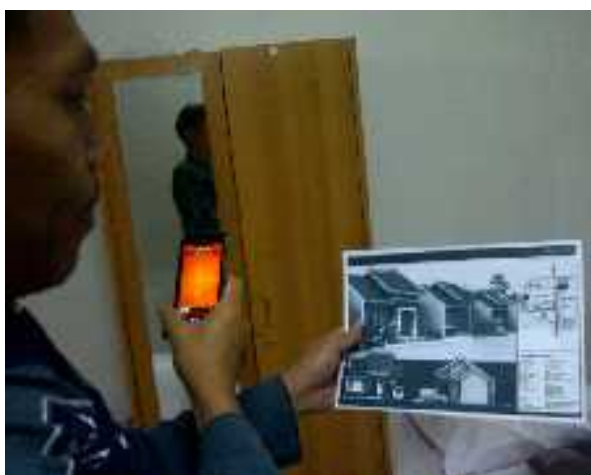

Gambar 3. Terjadi error pada saat pelacakan dengan gerakan yang tidak stabil

Dalam pengembangan dan perbaikan terhadap permasalahan diatas, maka pada penelitian ini metode Kalman Filter akan diterapkan untuk memperbaiki noise dalam pelacakan markerless sebuah objek brosur yang berbasiskan augmented reality sehingga proses pendeteksian objek menjadi stabil.

\section{Metoda Penelitian}

Tahapan penelitian mengacu pada penelitian yang dilakukan peneliti sebelumnya namun peneliti menambahkan sebuah metode yang akan menjawab dari permasalahan yang ada. Adapun rancangannya adalah seperti pada gambar 4 berikut :

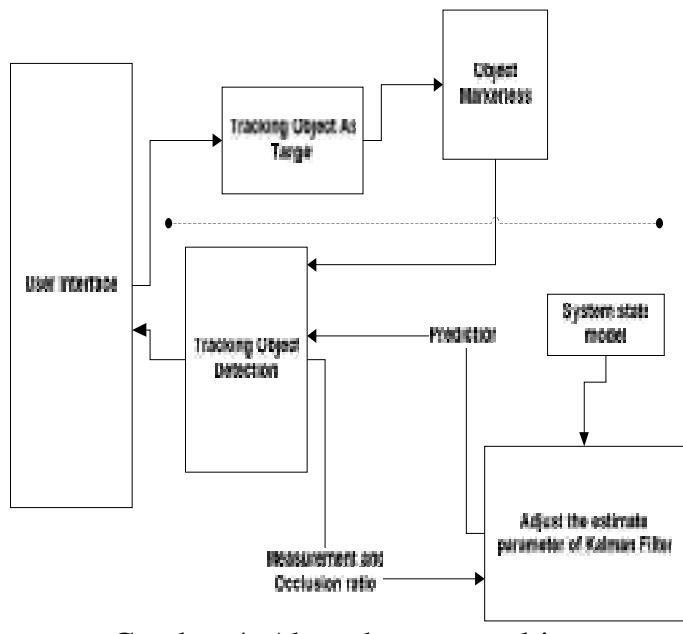

Gambar 4. Alur tahapan peneltian

Pada saat user melakukan tracking menggunakan aplikasi mobile, user mengarahkan (pencarian marker) terhadap objek (brosur) yang akan di tracking. Pada 
proses marker akan dideteksi dan dilakukan pencocokan marker / bidang ilustrasi, kemudian ditentukan posisi dan orientasi objek 3D, jika sesuai akan tampil informasi / rendering 3D objek yang diinginkan berdasarkan perbaikan metode kalman filter.

\section{Hasil Penelitian}

Dari hasil penelitian ini diperoleh sebuah parameter pengukuran yang akan dilakukan perhitungan secara manual menggunakan kalman filter untuk setiap iterasi. Maka hasilnya disajikan pada table 3.1 berikut

\begin{tabular}{|c|c|c|c|c|c|c|c|c|c|c|}
\hline \multirow[b]{3}{*}{ k } & \multicolumn{9}{|c|}{ Tabel 3.1 Perhitungan kalman filter } & \multirow[b]{3}{*}{$P_{k}$} \\
\hline & \multirow[b]{2}{*}{$z_{k}$} & \multirow[b]{2}{*}{$\hat{x}_{k-1}$} & \multirow[b]{2}{*}{$P_{k}^{-}$} & \multicolumn{2}{|c|}{ Time Update } & \multicolumn{3}{|c|}{$\begin{array}{c}\text { Measurement } \\
\text { Update }\end{array}$} & \multirow[b]{2}{*}{$\hat{x}_{k}$} & \\
\hline & & & & $\hat{x}_{k}=\hat{x}_{k-1}$ & $P_{k}^{-}=P_{k-1}$ & $K_{k}$ & $\hat{x}_{k}$ & $P_{k}$ & & \\
\hline 1 & 0.285 & 0 & 1 & 0 & 1 & 0.909 & 0.259 & 0.091 & 0.259 & 0.091 \\
\hline 2 & 0.005 & 0.259 & 0.091 & 0.259 & 0.091 & 0.476 & -0.187 & 0.048 & -0.187 & 0.048 \\
\hline 3 & 0.005 & -0.187 & 0.048 & -0.187 & 0.048 & 0.323 & 0.026 & 0.032 & 0.026 & 0.032 \\
\hline 4 & 0.046 & 0.026 & 0.032 & 0,026 & 0.032 & 0.244 & 0.005 & 0,024 & 0.005 & 0.024 \\
\hline 5 & 0.250 & 0.005 & 0.024 & 0.005 & 0.024 & 0.196 & 0.049 & 0.020 & 0.049 & 0.020 \\
\hline 6 & 0.320 & 0.049 & 0.020 & 0.049 & 0.020 & 0.164 & 0.058 & 0.016 & 0.058 & 0.016 \\
\hline 7 & 0.340 & 0.058 & 0.016 & 0.058 & 0.016 & 0.141 & 0.056 & 0.014 & 0.056 & 0.014 \\
\hline 8 & 0.480 & 0.056 & 0.014 & 0.056 & 0.014 & 0.123 & 0.076 & 0.012 & 0.076 & 0.012 \\
\hline 9 & 0.410 & 0.076 & 0.012 & 0.076 & 0.012 & 0.110 & 0.062 & 0.011 & 0.062 & 0.011 \\
\hline 10 & 0.450 & 0.062 & 0.011 & 0.062 & 0.011 & 0.099 & 0.062 & 0.010 & 0.062 & 0.010 \\
\hline & & & & & & & & & & \\
\hline & & & & & & & & & & \\
\hline & & & & & & & & & & \\
\hline 60 & 0.530 & 0.062 & 0.010 & 0.062 & 0.010 & 0.090 & 0,071 & 0.009 & 0.071 & 0.009 \\
\hline
\end{tabular}

Selanjutnya dilakukan pengujian menggunakan aplikasi yang telah dirancang menggunakan matlab. Adapun hasil penelitian diawali dengan membangun sebuah model dalam mendeteksi sebuah objek image (brosur) dalam memperoleh data pengukuran. Data diperoleh dari hasil tracking kamera sehingga diperoleh data tracking yang disajikan pada Gambar 3.1

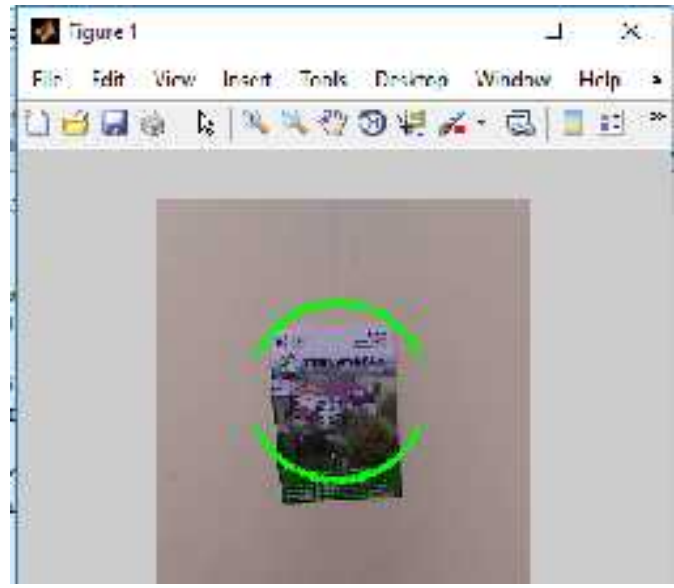

Gambar 3.1. Data Tracking
Dari Gambar 3.1 terlihat bahwa pergerakan objek image (brosur) dapat ditracking dengan baik. Selanjutnya pada gambar 3.2.a dan gambar 3.2.b terlihat ada noise

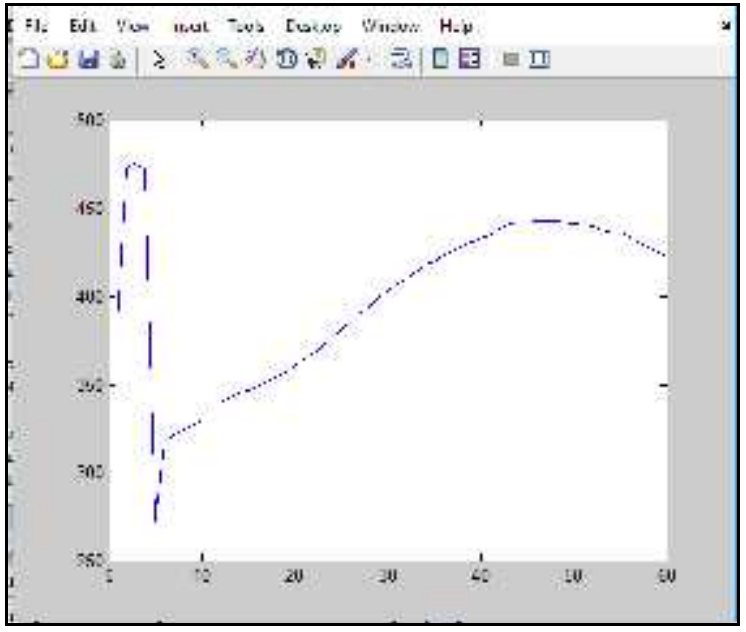

Gambar 3.2.a Noise posisi objek 


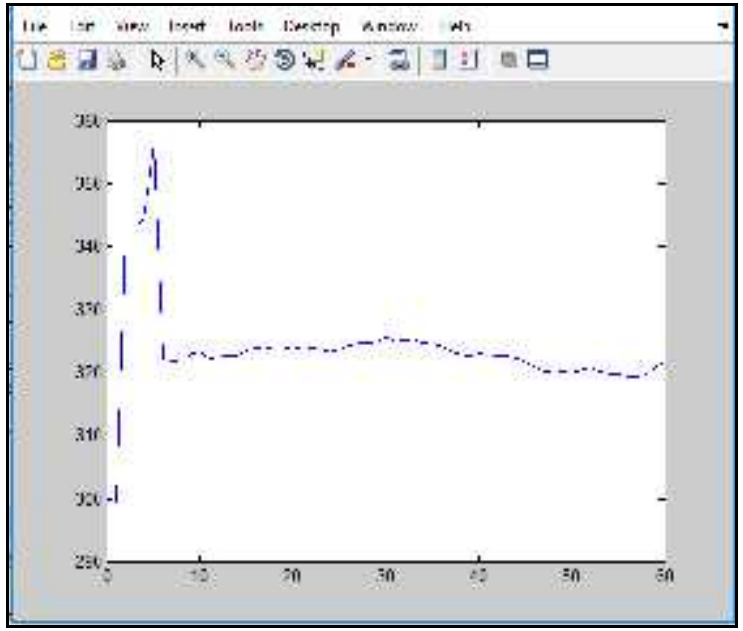

Gambar 3.2.b Noise 60 iterasi

Pada penyajian Gambar 3.3 diperoleh data awal yaitu grafik hasil observasi sepanjang 60 iterasi yang akan diperbaiki noise nya pada tahapan selanjutnya dengan menggunakan metode kalman filter



Gambar 3.3. Grafik Data Model

Selanjutnya dilakukan perbaikan dengan menyisipkan metode kalman filter, dan dilakukan tracking yang tampil seperti pada gambar 3.4 berikut.



Gambar 3.4. Data Tracking Kalman Filter

Setelah dilakukan tracking, sehingga diketahui hasil perbaikan noise menggunakan kalman filter yang tersaji pada gambar 3.5 berikut.

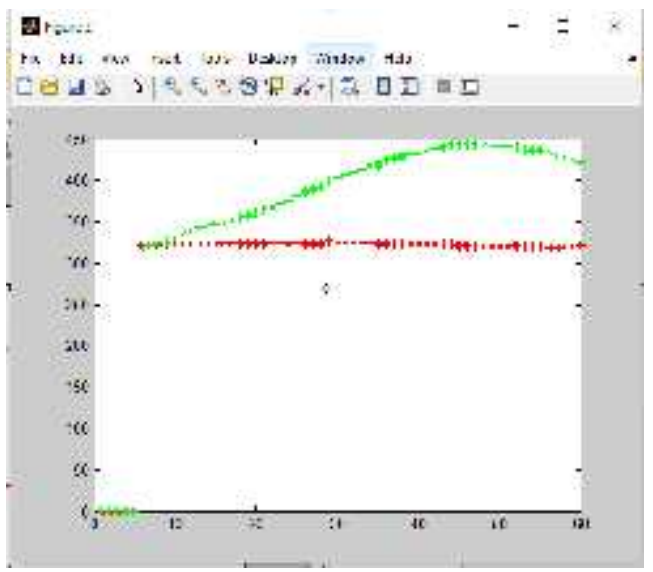

Gambar 3.5. Hasil Perbaikan

\section{Kesimpulan}

Setelah menyelesaikan aplikasi tahap awal, maka penulis dapat menarik kesimpulan sebagai berikut :

1. Telah diperoleh sebuah model dalam mendeteksi sebuah objek image (brosur) dalam memperoleh data pengukuran. Data diperoleh dari hasil tracking camera sehingga diperoleh data tracking.

2. Diperoleh perbaikan noise dengan menggunakan metode kalman filter sehingga diperoleh informasi kestabilan dalam proses tracking. 


\section{Saran}

Dalam hal ini penulis ingin memberikan beberapa saran yang mungkin berguna untuk pengembangan lebih lanjut yaitu :

1. Dalam penelitian ini tidak sampai kepada tahap tampilan augmented reality karena kemampuan penulis baik dari segi waktu dan pengerjaan.

2. Deteksi objek dapat dikembangkan secara multitracking, sehingga perbaikan data dengan menggunakan metode kalman filter cakupannya lebih luas.

3. Mengembangkan aplikasi dengan menguji selisih noise, dari data awal menjadi data setelah diperbaiki dengan metode ini.

\section{Daftar Pustaka}

[1] Rahmadi Kurnia. 2009. Penjejak Target Benda Pada Gerakan Linier Berdasarkan Warna. SNATI 2009. ISSN: 1907-5022

[2] Gunara, Andra, Tritoasmoro, Iwan Iwut dan Jangkung. 2007. Analisa Perbandingan Reduksi Noise Pada Citra Antara Discrete Wavelet Transform (DWT) Dengan DualTree Complex Wavelet Transform (DTCWT). Seminar Nasional Sistem dan Informatika, SNSI07-02

[3] Wiwin Sulistyo, Yos Richard Bech, Filipus Frans. 2009. Analisis Penerapan Metode Median Filter Untuk Mengurangi Noise Pada Citra Digital. Universitas Kristen Satya Wacana. KNS\&I09-035

[4] Murien Nugraheni. 2010. Aplikasi Transformasi Watershed Untuk Segmentasi Citra Dengan Spatial Filter Sebagai Pemroses Awal. Fti Uad. semnasIF 2010. ISSN: 19792328

[5] Asep Suherman, Fitriyani. 2013. Analisis dan Implementasi Hand Tracking Menggunakan Kalman Filter pada Augmented Reality Studi Kasus : Simulasi Alat Musik Tradisional Calung. Telkom University, Bandung ISSN : $2407-6511$

[6] Taupik, NurJayadi. 2014. Aplikasi Mobile Android untuk Pemasaran Perumahan Menggunakan Metode Markerless Augmented Reality pada PT. Alifa Citra Mulia. Jurnal Satin STMIK Amik Riau. ISSN: .2252-4258 